
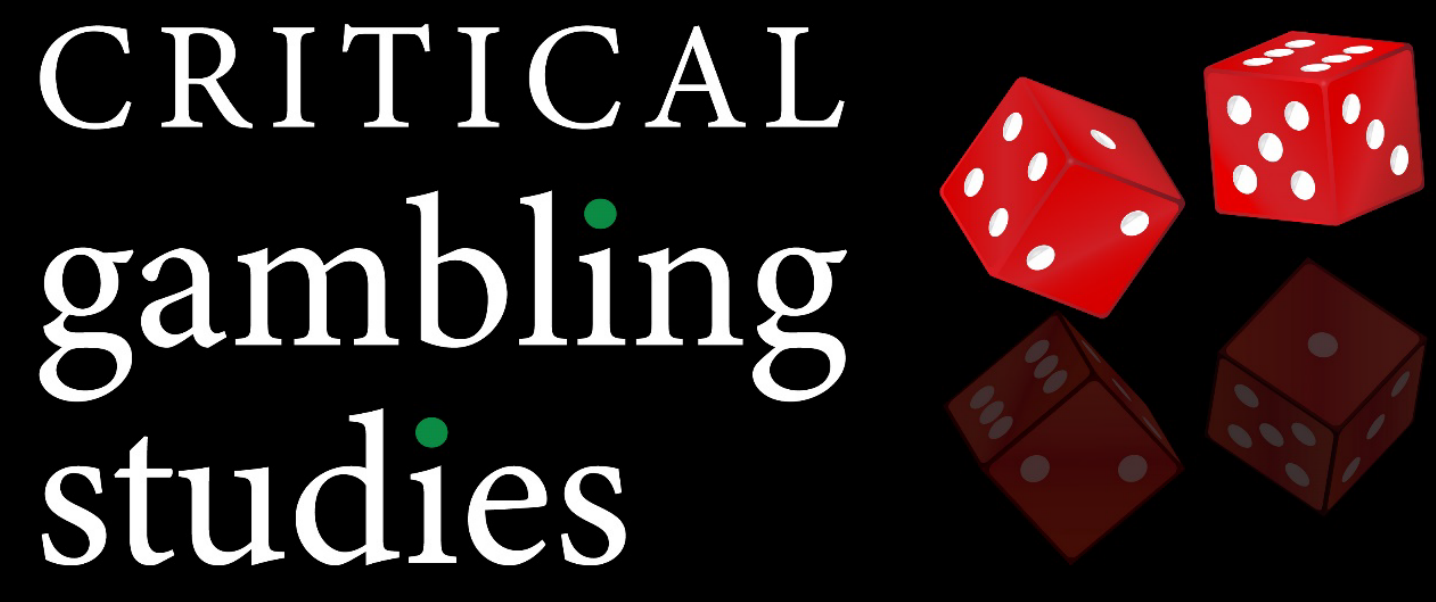

ISSN: 2563-190X. Available Open Access at https://criticalgamblingstudies.com

Social Representations of Responsibility in Gambling among Young Adult Gamblers: Control Yourself, Know the Rules, do not become Addicted, and Enjoy the Game...

Annie-Claude Savard, Mélina Bouffard, Jean-Philippe Laforge, Sylvia Kairouz

APA Citation: Savard, A.-C., Bouffard, M., Laforge, J.-P., \& Kairouz, S. (2022). Social

Representations of Responsibility in Gambling among Young Gamblers: Control Yourself, Know the Rules, Do not become Addicted, and Enjoy the Game. Critical Gambling Studies, 3(1), 58-70. https://doi.org/10.29173/cgs88

Article History:

Received 2020-12-18

Accepted 2022-01-05

Published 2022-03-07 


\title{
Social Representations of Responsibility in Gambling among Young Adult Gamblers: Control Yourself, Know the Rules, do not become Addicted, and Enjoy the Game...
}

\author{
Annie-Claude Savard ${ }^{\mathrm{a}}$, Mélina Bouffard ${ }^{\mathrm{a}}$, Jean-Philippe Laforge ${ }^{\mathrm{b}}$, Sylvia Kairouz ${ }^{\mathrm{b}}$ \\ ${ }^{a}$ Laval University \\ ${ }^{b}$ Concordia University
}

\begin{abstract}
The responsible gambling approach is the subject of significant debate in the scientific community due to its tendency to individualize responsibility, focusing heavily on the gambler's responsibility for gambling-related harm. Despite the gambler, and their responsibility, being the focus of responsible gambling discourse, their voices and perspectives remain largely absent. This study aims to address this limitation by documenting the social representations of the concept of responsibility held by gamblers themselves. How does the gambler perceive the concept of responsibility? Do they have an individual-centred understanding of this concept or are they able to distinguish their individual responsibility from that of the other stakeholders? This qualitative research is based on semi-structured interviews with 30 young adults (aged between 18 and 30 years old) who participated in gambling activities in the year preceding the research interview (2018). The results reveal that the social representations of responsibility held by gamblers fit into five categories: self control, knowing the rules and making the right decision, enjoying the game, not becoming an addict, and preventing harms related to gambling. All of these categories were found to be rooted in an individual perspective of responsibility. These results are discussed in light of the process of constructing the social representations of responsibility within the responsible gambling approach and in a neoliberal context.
\end{abstract}

Keywords: Responsibility, gambling, social representations, young adults, neoliberalism

Article History: Received December 18, 2020; Accepted January 5, 2022; Published March 7, 2022

Available Open Access from https://doi.org/10.29173/cgs88

\section{Introduction}

For more than 20 years, the revenue generated by the gambling industry has been exponentially growing. In 2015, the global gambling industry's revenue was estimated at 430 billion US dollars (Statista, 2020). In 2019, estimates forecast revenues of 495 billion US dollars (Statista, 2020), a 15\% increase over the previous year. In Canada, the gambling market totaled 14.97 billion US dollars in 2019 followed by a drop in 2020-21 due to the pandemic to 12.54 billion US dollars (Statista, 2022). In Québec, this industry generated 2.74 billion dollars in annual revenues for the State monopoly in 2020, followed by a decrease in 2021 due to the pandemic to 1.41 billion (Loto-Québec, 2021). Whether through taxation or state monopoly, gambling is a major revenue source for governments in countries where gambling is legal. As per Canada's criminal code (LRC (1985), ch. C-46, art. 207), each of the provinces has the authority to manage and conduct gambling through their monopolies. Other actors such as charitable and religious organizations or the board of a fair or an exhibition holding a license can also be authorized to operate gambling activities. However, in the case of online gambling, provincial state monopolies compete with out-of-country operators in an unregulated gray market. This lucrative entertainment industry, while contributing to the financial health of governments, is associated with the production of harms and problems for individuals and society. For example, in Quebec, $1.8 \%$ of gamblers are estimated to be at moderate risk of, or are currently experiencing, gambling-related problems (Kairouz \& Nadeau, 2014). Moreover, Fielder, Kairouz, and Costes (2019) have shown that, despite representing a small proportion of gamblers, those experiencing difficulties in relation to their gambling habit contribute disproportionately to the revenues of the gambling

\footnotetext{
${ }^{1}$ Corresponding author. Email: annie-claude.savard@tsc.ulaval.ca
} 
industry, accounting for $32 \%$ to $40 \%$ of total spending on gambling in Germany, Quebec, and France.

\section{Gambling and Young Adults}

Earning money is highly encouraged in a neoliberal society (Dormeau, 2020). Young adults' relationship with gambling thus seems to be marked by the flagship values of contemporary neoliberal ideology that colour the context in which gambling activities take shape. Being able to win money or gain status is a very powerful allure, especially for young people as they may not have the experience or the ability to restrain themselves when it comes to gambling (Gainsbury, 2012).

As underlined by Calado and colleagues (2017), gambling rates increase progressively with age, particularly in the transition from young adults to later adulthood. As shown in gambling studies conducted in many industrialised countries, young adults engage in gambling at a higher rate than the general adult population (Calado et al., 2017; Molinaro et al., 2014). Young people are now more than ever susceptible to being drawn in to gambling due to the availability of remote forms of gambling via their smartphones or internet; this is widely available compared to previous generations (Griffiths \& Parke, 2010). They are also targeted by marketing campaigns which can steer them towards gambling by distorting the social and financial rewards of gambling (Molinaro et al., 2014). Indeed, advertisements on social media, use of celebrities to promote gambling, and the opportunity to make substantial financial gains from gambling, are all powerful marketing tools that are very effective on young people (McMullan \& Miller, 2009). The values put forth in these messages are particularly appealing to young gamblers (Binde, 2014; McMullan \& Miller, 2009).

This greater engagement of young adults in gambling happens at the conjunction of discourses in gambling promotion and responsible gambling. Furthermore, young adults' experiences of gambling occur during a developmental stage when they tend to explore their environment, and construct their relations to the self, to social norms and expectations.

\section{The Responsible Gambling Approach}

Responsible gambling is rooted in the Reno Model IIV (i.e., the Reno Model), which serves as a guide for developing and implementing prevention initiatives in the specific area of gambling (Blaszczynski et al., 2004; Blaszczynski et al., 2008; Ladouceur et al., 2016; Ladouceur et al., 2017). For decades, the guidelines of the Reno Model have been used as standards for developing and implementing policies related to gambling offerings and prevention. The general principles underlying the model are "The ultimate decision to gamble resides with the individuals and represents a choice, and to properly make this decision, individuals must have the opportunity to be informed"
(Blaszczynski et al., 2004, p. 311). Initiatives stemming from this approach are thus generally based on a set of strategies aiming to provide access to information and support resources and supporting the gambler in developing better self control (e.g., limiting their bets or gambling time), monitoring their gambling habits, practicing self- exclusion from gambling venues, making informed decisions, and asking for support.

\section{Responsible Gambling and Individual Responsibility: A Critique}

The emphasis on individual responsibility is the main critique concerning responsible gambling: advocates of "Reno I-IV follow a consistent emphasis on individual responsibility, framed as personal control and autonomy for informed choice and focused on problem gamblers who manifest clinical symptoms of impaired control" (Hancock \& Smith, 2017, p. 8). Indeed, the responsible gambling approach raises significant concerns, specifically gambler's over- accountability for the harms associated with their gambling behaviour, and the exoneration of other stakeholders involved in the gambling industry, including the industry itself and the governments benefiting from it financially (Hancock \& Smith, 2017; Livingstone, et al., 2014; Miller et al., 2016; Reith, 2007; Reith, 2008; Smith, 2013; Yani-deSoriano et al., 2012). In fact, it appears that this approach favours a process of attribution, or even a transfer, of the responsibility of harm onto the consumer (Alexius, 2017). Fiedler, Kairouz, and Reynolds (2021), who conducted an analysis of seven gambling operators in Germany, concluded that these programs, largely focused on individual responsibility, have been exploited by the gambling industry to promote the operators' "corporate social responsibility." In fact, the measures that these programs offer were revealed to be ineffective for supporting gamblers in reducing gambling-related harm. Furthermore, these limitations of the measures can primarily serve the financial interests of the gambling industry.

This type of process can be linked to key features of neoliberalism, which "has redefined the relationship between the economy, the state, society and individuals. ... The ideology of self-responsibility has been especially significant since it [...] places the merit of success and the burden of failure on isolated individuals" (Fine \& Saad-Filho, 2017, p. 697). It is no longer up to the state to look after the welfare of the citizen, but to the citizen, henceforth the consumer citizen, to behave in a rational and responsible manner. Thus, by emphasizing key concepts such as accountability, empowerment, self- determination, and freedom of choice, the neoliberal ideology places the entire responsibility for actions on the individual. Consequently, more than ever, in the current economic and political context surrounding gambling, the gambler is considered a consumer who must be responsible for their actions, especially within a neoliberal society where gambling, an activity practiced 
by a majority of individuals, is synonymous with profits: "It is no longer the prerogative of the industry, the state, or the court to restrict the consumption of gambling this is now up to the individual, who becomes responsible for his or her own fate at the tables" (Reith, 2008, p.153). The same mechanisms, whether through the responsible gambling approach or the neoliberal ideology which characterizes our societies, will thus inevitably set the global environment in which the gambler's relationship with gambling is actualized, including their relationship to responsibility.

The construction and dissemination of this individual approach to responsibility has an impact beyond the role of the industry and governments. As highlighted by Reynolds and colleagues (2020) in a recently published scoping review, the scientific literature on responsible gambling, coming mainly from the fields of psychology and psychiatry, is also essentially focused on individual responsibility and the accountability of gamblers. The responsible gambling approach is strongly supported by research in these fields. This observation raises the veil on the role and responsibility of the scientific community in the construction and maintenance of the hegemonic conception of responsibility: "responsibility for the gambling- related harm is actively constructed and reproduced in a hegemonic way that situates the main responsibility for the emergence and handling of gambling-related harm on the individual gambler" (Alexius, 2017, p. 462). In fact, studies have documented how the strong predominance of disciplines such as psychology or psychiatry, which are heavily focused on the individual (Reynolds et al., 2020), or even the presence of connections between research and the gambling industry in funding gambling studies (Cassidy, 2020; Adams, 2016; Cassidy, 2014; Hancock \& Smith, 2017), have resulted in a body of gambling research focused on the individual responsibility and accountability of gamblers. Studies of young adult gamblers are no exception to this trend. Indeed, a majority of studies conducted with this population come from the field of psychology and are rooted in a positivist perspective. For example, a significant number of studies examine the impact of individual risk factors on the adoption of gambling behaviours and the etiology of problematic gambling (Hollén et al., 2020; Dowd et al. 2020; Carbonneau et al., 2015; Edgerton et al., 2016; Scholes-Balog et al., 2016). In doing so, they endorse an individual approach to responsibility in research on young adults. Consequently, this trend keeps the responsibility of other stakeholders in the shadows.

\section{Questions and Objectives Addressed in the Study}

Although gamblers are at the core of responsible gambling strategies, whether via making them bear the entire burden of responsibility for their behaviour and the harms associated with gambling, or challenging this accountability, one fact remains: their voice remains largely unnoticed in the dominant debates, the field being largely dominated by positivist quantitative research. This gap raises crucial research questions. These include: How do gamblers understand the concept of responsibility in the contemporary gambling landscape? How do young adults build their representation of the concept of responsibility while building their relations to the self and to social norms? Do they have an individual-focused understanding of this responsibility or are they able to distinguish their individual responsibility from that of other stakeholders? Do they believe that responsibility for their gambling behaviours rests entirely on their shoulders, or is it shared? Is this individualization of responsibility reflected in their representations of the concept? These are precisely the questions addressed by this study. By adding the perspective of gamblers to the conversation about the concept of responsibility and responsible gambling, this study aims to document young adult gamblers' representations of the concept of responsibility.

In discussion, the representations of the concept of responsibility will be analyzed in light of the concept of individual responsibility within the responsible gambling approach and in regard to the primacy of individual responsibility within contemporary neoliberal ideology.

\section{Theoretical Framework: The Theory of Social Representations}

A social representation is an organized, dynamic, and evolving collection of information, opinions, attitudes, and beliefs shared by a group of actors related to a particular object (Moscovici, 1961). It is constructed within the social and ideological context surrounding the actors in question (Moscovici, 1961; Abric, 2003; Clémence, 2003). More specifically, social representations, considered as systems of meanings, are constructed at the intersection between interactions and discourses that are present in the social space (Jodelet, 1989). Social representations emerge as regulators in social interactions and their conceptualisation can vary from one person to another depending on their perceptions, thus influencing the discourse (Moliner \& Guimelli, 2015). For instance, the discourse on responsible gambling "circulate[s] in the discourse, [is] carried by words, conveyed in the publicised messages and images, crystallized in conducts and the various material and spatial arrangements" (Jodelet, 1989, p. 45). It is through selfidentification with a given discourse that social representations are internalized by individuals (Moliner \& Guimelli, 2015). Once the social representations are rooted in an individual's system of meanings, they become referents for decision-making and action. In this study, the object of social representations addressed is the concept of responsibility in the specific context of gambling. Since the content and structure of a representation depend on the relationship individuals 
maintain with the social space, i.e., their role and position in the social environment (Jodelet, 1994), this study specifically focuses on the social representations of the concept of responsibility maintained by gamblers.

The founding approach, proposed by Moscovici and commonly referred to as sociogenetics (Moscovici, 1961), is primarily concerned with describing the conditions and processes involved in the emergence of representations (Moliner \& Guimelli, 2015). This approach proposes two processes involved in the construction of social representations. These processes allow us to understand the construction of social representations and how they are integrated within a historical, social, economic, and political context. The first process, objectivation, refers to the way that a new object, through communications and discourses about it, will be simplified, depicted, and schematized; "through a phenomenon of selective construction, the various aspects of the object are extracted from their context and sorted according to cultural and normative criteria [corresponding to the value system of the group]" (Moliner \& Guimelli, 2015, p. 6, author's translation). These elements then form a coherent whole, functioning as the reality for the individuals of a particular social group, which is composed of individuals who share similar position socially, in this case, the group of young adults. The anchoring process subsequently completes the objectivation process. Anchoring refers to "the way the new object is integrated into the preexisting way of thinking of individuals and groups. [...] the new object will be assimilated with known forms from familiar categories. At the same time, it will become part of an existing network of meanings" (Moliner \& Guimelli, 2015, p. 7). Anchoring thus sheds light on how the construction of a social representation is rooted in the cultural and normative referents of a social group.

\section{Methodology \\ Research Protocol and Material}

This qualitative study falls in the realm of descriptive studies of social representations (Moliner \& Guimelli, 2015). As the study is part of a research program focused on the issue of responsible gambling specifically in the young adult population, the convenience sampling is composed of 30 young adults aged 18 to 30 years old who participated in gambling activities in the year preceding the research interview (2018). These young adults were recruited in the province of Québec through electronic mailing lists of one university $(n=17)$ and two colleges $(n=8)$ and by direct solicitation in one casino $(n=5)$. In the first case, interested individuals could respond electronically to a recruitment e-mail created for this study to indicate their interest in taking part in the study and to make an appointment. In the second case, interested young adults had the option of leaving their e-mail or phone contact information with members of the research team in order to be contacted, or receiving a pamphlet detailing the information about the study and the researchers' contact details. The project was approved by the research ethics committees of Laval University as well as those of the two participating colleges in Québec City.

Individual research interviews took place from midApril to early July 2019. They were conducted by the principal investigator and members of the research team trained in social work, criminology, and sociology. Each research meeting began with a presentation of the study objectives and the consent form. The results reported in this article are derived from the material collected through the spontaneous evocation exercise conducted during the research interviews. This exercise consists of using an inductive word as a starting point, in this case the word "responsibility," and asking participants to spontaneously identify words or expressions that come to mind when the interviewer states the inductive word. Combined with an in-depth conversation, spontaneous evocation is a recognized method for accessing the semantic universe of social representations and their content (Abric, 2003). Therefore, at the beginning of the interviews, each participant was asked to spontaneously identify the first three words or expressions relating to gambling that came to mind when the interviewer said the word "responsibility." Each word or expression was then discussed in detail to deeply understand the meaning of the words or expressions identified by the participant and their connections to the concept of responsibility. This exercise lasted approximately 30 to 60 minutes.

\section{Analysis}

Interviews were recorded on digital audio media and then transcribed. The material was subsequently codified using N'Vivo software, and a thematic content analysis was conducted to identify the units of meaning using an inductive approach (Paillé \& Muchielli, 2016). The inductive approach is defined as "a set of systematic procedures for processing qualitative data, these procedures being essentially guided by research objectives" (Blais \& Martineau, 2006, p. 15). The material collected through the spontaneous evocation method was subjected to a content analysis in combination with the information registered through the in-depth conversation in order to identify the significance that participants attribute to each one of the evocative words. The content analysis focused on the meaning of these words to the participants and how they associated them with the concept of responsibility. This process highlighted the thematic categories associated with the concept of responsibility reported by participants. This analysis was conducted while respecting the semantic world of participants, i.e., by considering the words and expressions identified by them. 


\section{Results}

\section{Participants}

The sample is composed of 30 young adults who had gambled in the year preceding the interview, with 24 identifying themselves as male, five as female, and one participant having selected "other gender identity" 2 . The average age was 21.5 years old $(\min =18$; $\max =26)$ and a majority $(n=24)$ were single. Most participants were university $(n=17)$ or college students $(n=8)$. A large majority of participants reported living with their parents $(n=16)$, or with other people $(n=11)$, and fewer reported living alone $(n=3)$. The majority considered themselves comfortable or very comfortable financially ( $n=18$ ) or considered their income sufficient to meet their basic needs $(n=10)$. With regard to income, 18 were employed part-time or seasonally, seven had full-time jobs, and five declared other sources of income. Hence, the results of the study should be interpreted with caution given the homogeneity of the sample in terms of gender, ethnicity (White), occupation (student) and socioeconomic status.

The sample showed an interesting diversification in terms of gambling activities, with a majority having engaged in three or more different gambling activities $(n=22)$ in the previous year. Even though the frequency of gambling varies by gambling type, the maximum frequencies for any single activity reported by the participants in the study were less than once a month $(n=4)$, once a month $(n=13)$, once a week $(n=5)$, more than once a week $(n=5)$ and almost/every day $(n=3)$. The most popular gambling activities were lottery and scratch tickets $(n=22)$, casino $(n=22)$, poker $(n=19)$ and sports betting $(n=19)$. Although a large number of participants reported gambling on lottery, this gambling activity did not emerge as the principal gambling activity referred to by participants during interviews. In this regard, only one participant exclusively gambled on lottery.

\section{The Social Representations of Responsibility}

The analysis revealed that the social representations of the concept of responsibility, as evoked by participants, can be divided into five main categories 1) self control, 2) knowing the rules and making the right decisions, 3) enjoying the game, 4) not becoming an addict, and 5) preventing harms. One main finding is that all of the categories concern individual responsibility. Table 1 presents the categories, and subcategories (if applicable), and all of the words and expressions evoked in reference to them.

Table 1. Words and expressions evoked according to the categories associated with social representations of responsibility

\begin{tabular}{|c|c|c|}
\hline Categories & Sub-categories & Words or expressions \\
\hline \multirow[t]{5}{*}{ Self control } & Financial & $\begin{array}{l}\text { Money, stop, bankroll management, budget, know your financial limits, } \\
\text { conscience, control, debt, savings, save, excess, bankruptcy, financial, manage, } \\
\text { honesty, responsible gambling, judgment, limits, long-term, moderation, } \\
\text { monetary, morality, do not exceed your initial bet, do not overdo it, don't spend } \\
\text { too much, do not bet too much, concept of money, plan, be cautious, } \\
\text { reasonable, reluctance, satisfaction, knowing when to stop, security, watching } \\
\text { your wallet }\end{array}$ \\
\hline & $\begin{array}{l}\text { Priorities and } \\
\text { responsibilities }\end{array}$ & $\begin{array}{l}\text { Adult, money, maturity, mature, reasonable, sense of priorities, serious, provide } \\
\text { for needs, your life }\end{array}$ \\
\hline & $\begin{array}{l}\text { The self (emotions, } \\
\text { behaviours) }\end{array}$ & Calm, conscious, control, to not drink, personal, self-control \\
\hline & Time & Control, excess, low gambling, do not finish too late, reasonable, time \\
\hline & Social network & Watch friends \\
\hline $\begin{array}{l}\text { Knowing the rules } \\
\text { and making the } \\
\text { right decisions }\end{array}$ & & $\begin{array}{l}\text { Assume, be careful to not get involved in the process, conscience, control, } \\
\text { honesty, meticulous, precaution, prevention }\end{array}$ \\
\hline Enjoying the game! & & Attentive, good gambler, fun \\
\hline $\begin{array}{l}\text { Not becoming an } \\
\text { addict }\end{array}$ & & Addiction, dependence \\
\hline Preventing harms & & Prevention \\
\hline
\end{tabular}

The category of "self control" was clearly the most reported by participants, referring to 57 different words or expressions, in comparison to the other categories to which were associated with between one and eight

\footnotetext{
${ }^{2}$ Given that the convenience sample of the study included only five participants who identified as female and one participant who
}

words or expressions. Furthermore, the analyses revealed five sub-categories characterizing the category of self control: financial control, control over priorities and responsibilities, control over time, control

identified as non-binary, it was not possible to conduct any gendered analysis. 
of the self (emotions and behaviours), and surveillance of the social network. Among these sub-categories, the financial aspect was the most reported with 35 associated words or expressions.

The following results are organized according to the five categories that emerged from the thematic content analysis as associated with the social representations of the concept of responsibility.

\section{Self control}

As mentioned before, self control is the category most associated with the social representation of the concept of responsibility among participants.

\section{Financial}

By far the most often mentioned aspect by gamblers, financial control was evoked through 35 different words or expressions. The core idea of financial control was to essentially establish a certain limit on the amount of money that the so-called "responsible" gambler must respect. This self-set limit was evoked in several ways: "do not overdo it," "do not spend too much," "be reasonable," or, even, "be cautious." In all cases, the common denominator was the control the gambler must exercise on themself in order to establish their own financial limits.

"If you really want to limit yourself, well, you know, really the biggest responsibility, I believe that when you gamble, it's really watching your own spending so you don't start getting yourself into debt." (Geneviève, F, 21, lottery/scratch ticket and slot machines)

"In my opinion, that's what is most important. I say to myself: "If you have a budget, you are saying to yourself: "Right, I have $\$ 20, \$ 20, \$ 20$, that's it, that's all, no more, no less. [...] Once that budget is well established, well centred, then I tell myself that it can be controlled. And without it, well, minimizing the impacts on our life I would say." (Jacob, M, 23, lottery/scratch ticket, casino games, bingo, slot machines)

Ultimately, for some gamblers, control of spending seemed to be the condition that determined whether a gambler was responsible or not, as explained by Guillaume ( $M, 27$, poker, slot machines): "Because normally, if you are responsible you should respect your own limit, right, respect your budget."

\section{Priorities and Responsibilities}

Expressions such as "have a sense of priorities," "being serious," or "mature" demonstrated the responsibility to keep control over one's priorities. The analysis of the social representations of the concept of responsibility made it possible to introduce a level of reciprocity between priorities and financial control.
Thus, for Julien money must be used to meet his basic needs before gambling:

"Well, when there is rent to pay, you're better off paying the rent than well, you know, these types of things, for example." (Julien, $M$, 24, lottery/scratch ticket, bingo, poker, horse racing, sports betting, games of skill)

For Jacob, participating in gambling is seen as a potential risk for the gambler's future. This risk needs to be considered in the context of a sample of young adults, who are in a stage of life that involves making important decisions about the future, for example at the professional or personal level. It is thus by adopting responsible behaviours that the gambler would be able to protect themselves from future risks.

“...you're responsible for that. It's still your
future. [...] You're responsible for your life when
you are gambling. [...] for me, I think when you
gamble... often in some way, you are playing
with fire. You know, it's your life, it's your money,
it's your well-being, it's your comfort [...] That's
life." (Jacob, M, 23, lottery/scratch ticket, casino
games, bingo, slot machines),

Some participants said that age also plays a predominant role in the gambler's responsibility; as they reach age 18 they essentially inherit greater responsibilities, in particular that of controlling their gambling habits.

"[...] the law states that at 18 years old, you know, you become an adult, so... you step into another category. [...] That comes with responsibilities. [...] You know, what I am referring to, you know... we are saying, you know, you're responsible for, you know, for yourself, for staying level-headed, for... Well, it's a bit like that for gambling, you know, being careful to not... to gamble reasonably." (Catherine, F, 22, lottery/scratch ticket, slot machines, bingo)

The results presented here demonstrate how the gambler is responsible for controlling themself to be able to ensure their priorities. The gambler is responsible for their needs, well-being, and future. According to this logic, it would be irresponsible to spend on gambling before the needs and priorities of the gambler have been fulfilled, i.e., "The most important things in their life, such as you know, their education, their family." (Olivier, M, 18, lottery/scratch ticket, poker, slot machines, games of skill)

\section{The Self (Emotions and Behaviour)}

Beyond financial control and priorities, some participants evoked the responsibility of the gambler to 
control themselves on the emotional and behavioral levels. For Antoine being responsible is reflected, in particular, by the ability of the gambler to exercise control over themself:

"[...] I think that it is important to know how to control yourself and I think that from the moment that you know how to control yourself in gambling games... well then, you are more responsible. You are more responsible by controlling yourself, I think, yeah." (Antoine, $M$, 20, lottery/scratch ticket, casino games, bingo, poker, day trading, slot machines, sports betting)

Antoine and Jacob, added that the gambler must control their emotions and impulses to avoid getting carried away and spending without restraint:

"[...] because, sometimes you get carried away, but the goal is... another part of responsibility is to stay calm and not letting yourself get carried away." (Antoine, M, 20, lottery/scratch ticket, casino games, bingo, poker, day trading, slot machines, sports betting)

"Control yourself in the sense that you can't act on impulse, and say: "Go, let's go, let's spend it all [...] you have to have some restraint." (Jacob, $M$, 23, lottery/scratch ticket, casino games, bingo, slot machines)

\section{Time}

Time is another sub-category of control which emerged in gamblers' words through terms and phrases such as "excess," "low gambling," and "do not finish too late." Some participants, like Sophie, made reference to controlling gambling time through the question of frequency of gambling sessions. A responsible gambler is therefore one who gambles occasionally.

"[...] gamble a little bit, I mean... you know, you can gamble... I'm speaking for myself, you can gamble a bit here and there, not necessarily gamble every day, because it still comes back to the concept of control, which is the most important." (Sophie, F, 18, lottery/scratch ticket)

For Simon, he explains how limiting time spent gambling makes it possible to limit potential negative impacts on important areas of life.

"I think that it is much worse if you finish too late, like going to bed at 6 a.m., and, you know, if you were drinking and gambling, for example. You know, finishing late, I don't know, the next morning, you feel a bit like shit, if you are working and everything, it sucks." (Simon, M, 20, lottery/scratch ticket, casino games, bingo, poker, horse racing, slot machines, sports betting)

\section{Surveillance of Social Network}

In some cases, the responsibility related to control is not limited to the gambler's behaviour alone but also the behaviour of their social network. For example, Geneviève explains how she is sometimes given the responsibility of managing the spending of her gambling friends.

"Well, with my friends sometimes, some of them say: "Take my debit card because I don't want to spend any more." Then, it's often me who keeps everyone's cards, so they are limited a bit that way." (Geneviève, F, 21, lottery/scratch ticket and slot machines)

Although the category of control here takes on an interpersonal dimension, it's still the gambler's responsibility, whether it is the idea of relinquishing control of their finances to a "responsible" friend or even monitoring the spending of their peers.

All of the sub-categories of "self control" as a component of social representations of the concept of responsibility, in addition to being of the same category, have another aspect in common: They all rest on the gambler's shoulders and reflect the individual perspective of responsibility. As revealed in the participants' discourse, all the elements that are constitutive of the self control category are in line with the discourse often conveyed by the responsible gambling approach, mostly conveying an individual orientation to responsibility.

\section{Knowing the Rules and making the Right Decisions}

"Attention", "assume", "precaution", "meticulous." It is specifically through these words that participants referred to the gambler's responsibility to inform themselves about gambling and to know the rules of what they are engaging in to be able to make the right decisions. Thus, some emphasize the importance of being informed. For Jérôme, this was demonstrated through the time and attention he invests in preparation for sports betting:

\footnotetext{
"Yeah, well technically when I bet on sports, I always look at the statistics and the results a bit beforehand, meaning I am technically meticulous. I go by player and team statistics. It takes patience to do this since sometimes it can take a relatively long time." (Jérôme, $M, 22$, lottery/scratch ticket, casino games, blackjack, sports betting)
}

Louis highlighted how the gambler is responsible for knowing the rules of what they are getting involved in before gambling. 
"You know, you don't just gamble on anything. It's like, you gamble on something you know a minimum about, you know the rules and all because sometimes you see people going to the blackjack and they know nothing yet. They just put down money and [they] are like: "Holy shit, I won!" But they don't even know why they've won. Just make it so you are, that you at least understand the game you are gambling on, that you are aware of what game you are going to gamble on." (Louis, M, 19, casino games, blackjack, sports betting)

For some gamblers, it is more about knowing the mechanics beyond gambling games, such as chance. In the following quotes, Sylvain and Laurie explain how the gambler is responsible for knowing that it is impossible for them to control the odds of winning.

"We do sports bets or whatever gambling games we play, so when I think of responsibility, you know, I think that it's the responsibility of the person to know that, once again, they have no control over it, so they have to remind themselves or keep that in mind." (Sylvain, M, 26, lottery/scratch ticket, poker, sports betting)

"I think that you have to be responsible enough to be aware of this process. Yeah, even though it happened to you once [winning], it doesn't mean that it will happen again the next five times you hit the button." (Laurie, F, 21, lottery/scratch ticket, slot machines)

Being informed and knowing the rules seem to therefore be prerequisite conditions for those participants in making "responsible" decisions. This component of responsibility suggests that the gambler has to take responsibility for the risk and consequences associated with their decisions as Philippe stated.

"I believe that honesty and assuming responsibility allows me to say that we're not always going to spill the beans...We lost, we lost, it's not the dealer's fault, it's not the card's fault, it's not the fault of... Well, it's our fault in some way since we were gambling." (Philippe, $M, 21$, blackjack, poker, sports betting)

Knowing the rules, making the right decisions, and assuming responsibility for the risks associated with gambling seems the gambler's responsibility according to most of the participants of the sample group.

\section{Enjoying the Game!}

Through expressions such as "good gambler," "fun," and "attentive," the theme of pleasure emerged as one of the categories associated with the social representations of the concept of responsibility. Thus, for Olivier, it is the responsibility of the gambler to adopt an appropriate attitude and behaviours so that gambling remains pleasant.

"You know, poker and those kind of games, they are games you play with others, and these people enjoy playing these games, so it is important to be respectful of others and to play for fun, like everyone else." (Olivier, M, 18, lottery/scratch ticket, poker, slot machines, games of skill)

For Sylvain, he directly associates the concept of enjoyment with responsible gambling, or rather the lack of pleasure as an illustration of irresponsible gambling. Pleasure must be the main objective of gambling. When the fun fades away, the gambler's responsibility fades away with it.

"I see it in the sense that the main goal with gambling is to have some sort of fun, so if there is no longer fun, it's like it's no longer responsible gambling, so to speak, that's how I see it." (Sylvain, M, 26, lottery/scratch ticket, poker, sports betting)

Although according to some it is the gambler's responsibility to stay in the fun zone when gambling, for others, beyond the recreational sphere, it is also their responsibility to keep problems from arising.

\section{Not becoming an Addict...}

The concept of responsibility was also associated with the expressions "addiction" and "dependence" by some participants or, more widely, with the theme of gambling problems. Thus, according to some, it would be the gambler's responsibility to not "develop a dependence."

"Well, I would say in a sense, because when you are responsible, well, how do I say it, you are taking care of yourself, to not, you know, have this type of addiction to gambling." (Catherine, $F$, 22 , lottery/scratch ticket, slot machines, bingo)

"So, the idea is that when you start to have an
addiction, when you start to see that it is causing
too many things, too many unreasonable things,
if I may say so. Then, you probably have to take
responsibility..." (Paul, non-binary gender, 24,
lottery/scratch ticket, casino games, horse
racing, electronic gaming machines, sports
betting)

This fourth category of the social representations of the concept of responsibility highlights the idea of the gambler's accountability and the gambler's role in preventing the difficulties associated with gambling, including the "development of an addiction." 


\section{Preventing Harms}

Prevent the harms is the last category related to the social representation of the concept of responsibility that emerged from the spontaneous evocation exercise. From the point of view of the participant who stated this category, it would be the responsibility of both the gambler and the gambling operator.

"Well, in fact, it's the gambler's responsibility to be aware of it. But, for prevention, it's rather the [industry]'s responsibility. So there is an aspect of responsibility that is not just with the gambler, it is also with the state monopoly." (Alexandre, M, 19, lottery/scratch ticket, casino games, blackjack, slot machines, sport betting)

Prevention is the only category (mentioned by only one participant) that referred to a social representation of responsibility that was not exclusively the gambler's, but was shared with another stakeholder.

\section{Discussion}

The social representations of the concept of responsibility maintained by young adult gamblers will be discussed in relation to two key analytic themes: 1) individual responsibility within the responsible gambling approach and 2) the construction of individual responsibility within contemporary neoliberal ideology.

\section{Responsible Gambling and Individual Responsibility}

The results highlight that the social representations of the concept of responsibility maintained by the participants are shaped by five main categories: self control; knowing the rules and making the right decisions; enjoying the game; not becoming an addict; and lastly, preventing harms related to gambling. When questioned on their social representations of the concept of responsibility, the gamblers' evocations almost unanimously reflect that responsibility rests largely on individual control. This control takes many forms: financial, priorities and responsibilities, the self, gambling time, and finally, the surveillance of the social network. All in all, individuals have to control themselves to stay in the good gambler "zone" or, at least, to adopt socially acceptable gambling behaviours that have no impact on other spheres of life and are free from harm. Similarly, the other categories associated with the social representations of responsibility (being informed, enjoyment, not developing a problem, or even preventing harms) all come back to individual responsibility.

Careful analysis of the content of all the categories raised by the gamblers associated with responsibility, except the category "preventing harms", unequivocally demonstrates that the conception of responsibility shared by the young adult gamblers interviewed is essentially individual. Indeed, the categories that the gamblers associated with the concept of responsibility were perfectly in line with the individualizing principles of responsibility at the core of the Reno Model. Only the word "prevention," of all of the words evoked by participants, refers to the idea of a partially shared responsibility, in this case, with the gambling industry. It is clear that, although operators acknowledge in their discourse their share of responsibility with the gambler, they have not left their mark on the gamblers' social representations of responsibility. How is it possible that to the question "Thinking about the world of gambling, what are the first three words that come to mind when we say the word "responsibility?" the collective dimension of responsibility is so seldom evoked by participants? Where some might see an indicator of the effectiveness of the responsible gambling measures, or an indicator of "best practices" of the responsible gambling approach, we see instead serious concerns with the elision of collective responsibility. It appears unfair to put the weight of a social problem, which is part of a complex economic and political context, on the shoulders of individual gamblers. This conception of responsibility, entirely focused on the individual, indicates the internalization of a unidimensional discourse on responsible gambling that is maintained, whether consciously or not, by a multitude of stakeholders involved in, and concerned with, the issue of gambling: operators, governments, researchers, etc. Considering that the social representations of an object are constructed within social, economic, political, and ideological contexts (Moscovici, 1961, Abric, 2003, Clémence, 2003), we hypothesize that the principles and messages conveyed within the responsible gambling discourse have served as reference points for young gamblers in constructing their social representations of the concept of responsibility. It is thus from these "normative criteria" that the objectivation and anchoring processes took place and that the social representations of responsibility oriented toward individual responsibility maintained by young adult gamblers were constructed. These analyses are in line with the work of Alexius (2017), which documents the processes of attribution and transfer of responsibility of harms to the gambler. Indeed, although the gambler is the key actor required for the functioning and profitability of the economic-political system of gambling, there are clearly blind spots in terms of understanding their role and responsibilities (and those of other stakeholders) in this complex landscape. Young gamblers have internalized the message that it is the individual's responsibility to take action and make decisions that ensure harm-free gambling and prevent potential "addiction."

The results of this study align with concerns expressed by critical gambling studies scholars who have addressed the responsible gambling approach and its impacts on the over-responsibility placed on gamblers and, consequently, how easily other stakeholders in the gambling industry (in a wider sense) are absolved of any responsibility (Cassidy, 2020; 
Hancock \& Smith, 2017; Reith, 2008). These results highlight how young adult gamblers have constructed representations of responsibility as their sole responsibility as gamblers. Responsible gambling has, through a hegemonic conception of responsibility maintained and conveyed by gambling operators, governments, and the scientific community (Alexius, 2017), literally contributed to "shaping the self" of gamblers as well as their relationship to responsibility (Rose, 1999). This process refers to the construction of subjects as responsible gamblers.

\section{Individual Responsibility and Contemporary Neoliberalism}

Beyond the internalization of the principles of responsible gambling, the analysis of the representations of responsibility clearly highlights the imprint of the neoliberal ideology in their construction. Indeed, a closer look at the results allows us to postulate that social representations of responsibility are constructed across a much larger network of meanings, normative criteria, and shared values than the responsible gambling approach, which, in itself, is an embodiment of the contemporary neoliberal ideology.

From a mode of governance of conduct within a neoliberal rationality to a technique aimed at reinforcing an economic logic, the close links between individual responsibility and neoliberalism have been explored by many scholars (Fine \& Saad-Filho, 2017; Dormeau, 2019; Hache, 2007; Fournier, 2015; Rose, 1999). Through a variety of subtle mechanisms, neoliberalism has interfered with all spheres of life, including the most private ones. By infiltrating all social and individual spaces, neoliberalism's key concepts namely self-responsibility, empowerment, selfdetermination, self control and freedom of choice have become the background on which our cultural and normative referents are printed, thus constituting the "network of meanings" that will come to guide the objectivation and anchoring processes constructing the representations of the young adult gamblers (Dormeau, 2019). The fact that the young adults in this study report representations of responsibility that accurately reflect these key concepts is a powerful demonstration of how neoliberal ideology constructs their subjective relationship to gambling and responsibility.

This influence of neoliberal principles on individual subjectivity is also revealed through the categories associated with the social representations of responsibility evoked by the participants of the study. Indeed, categories such as "self control," "making the right decisions," and "not becoming an addict," align perfectly with neoliberal ideology's concepts of selfdetermination, self-management, empowerment, and freedom of choice (Fournier, 2015). As Dormeau (2019) highlights "[...] neoliberal capitalism exploits the human as a whole, body, soul, emotions, attentions, namely by putting the individual at the core of its domination system, as the author of their own alienation" (p. 133, author's translation). These findings about how the principles of neoliberalism permeate the subjectivity of individuals, especially gamblers, echo the work of Casey (2021) and Reith (2004), who clearly outlined this process. It is based on such collective benchmarks (e.g., self-responsibility, self control, self-determination, empowerment) that gamblers take full responsibility for their gambling behaviours, making the right choices, controlling themselves, and even the harms associated with gambling, regardless of the social context and political economy in which their gambling behaviours take place (Fournier, 2015). It is within this particular context that young adults build their relation to gambling and responsibility, along an ongoing process of self-exploration and while they position themselves in regard to social norms.

However, if the gambler fails to individually impose responsible gambling limits, they are labelled, and label themselves, as "problematic," "pathological," or "dependent," and treated (note here the medical language) as if the problem is of a purely individual nature. The gambler is therefore responsible for ensuring they do not become abnormal (i.e., do not become addicted) (Hache, 2007). Further, as Dormeau (2019) underlines in an analysis of emotions in the neoliberal era, "even though tragedies have social, health, climatic causes, therefore exogenous causes, or to cite Épictète 'which do not depend on us', it is still within ourselves that we must draw in order to govern ourselves, to get out of it" (p. 139, author's translation). In doing so, the gambler is also responsible for finding solutions for potential gambling-related harms, without the overall context in which the problem is produced, nor the responsibility of other stakeholders, being addressed (Hache, 2007). Francis and Livingstone (2021) argue that this focus on individual responsibility in the responsible gambling discourse diverts our attention from those individuals who experience or are at risk of experiencing harm in relation to their gambling practices. Those are also the ones who generate the most revenue for the industry. In this context, the "good gambler" and "responsible gambler" become "the role model [...] individually responsible for his own wellbeing" (Hache, 2007) and the responsible gambling approach, rooted in the concept of individual responsibility, finds full legitimacy. In fact, this concept is founded on similar precepts as ones put forth under the dominant neoliberal ideology in terms of the established relationship between individuals and their responsibility.

Furthermore, promoting and imposing the responsible gambling approach oriented toward individual responsibility means taking for granted that everyone is equal in terms of the social expectations of performance, optimization, and self-management that neoliberalism imposes. It means ignoring the inequalities that configure the range of possible options and accessible resources available to each individual in order to meet these expectations (Castel, 2004). A 
gendered analysis of the way individuals relate to gambling and responsibility and of the potential underlying inequities is a much needed in future studies. Hence, a responsible gambling approach, as conceptualized in the Reno Model, implemented in a neoliberal society, presents a significant risk for further increasing these inequalities (Hache, 2007). Furthermore, as argued by Francis and Livingstone (2021, p. 1) "a discourse overwhelmingly favoring industry interests, has the potential to entrench and support harmful systems of exploitation and harm creation".

\section{Conclusion}

The results of this study are innovative in the sense that few existing studies have explored the concept of responsibility from the gambler's perspective. They clearly shed a light on how young adult gamblers internalized a discourse about responsibility that is situated at the intersection of a responsible gambling approach and neoliberal ideology. By doing so, this reflects an integration of a discourse that is meant to completely transfer the responsibility to the gambler, as suggested by Alexius (2017). The homogeneity of the discourses maintained by these young adults with regard to individual responsibility is also a clear example of the way in which the governance of individuals and their behaviors is actualized in early adulthood. This governance is deployed through a variety of institutions and actors. Hence, the complex gambling landscape and the multiplicity of the involved actors requires an equitable sharing of responsibility between different constituencies. Individual persons cannot solely bear the consequences of a social problem and scholars have an important role in pushing for this change to happen.

\section{References}

Abric, J.-C. (2003). L'analyse structurale des représentations sociales. In S. Moscovici \& F. Buschini (Eds.), Les méthodes des sciences humaines (pp. 375-392). PUF.

Adams, P. J. (2016). Moral jeopardy: Risks of accepting money from the alcohol, tobacco and gambling industries. Cambridge University Press.

Alexius, S. (2017). Assigning responsibility for gambling-related harm: Scrutinizing processes of direct and indirect consumer responsibilization of gamblers in Sweden. Addiction Research \& Theory, 25(6), 462-475. https://doi.org/10.1080/16066359.2017.1321739

Binde, P. (2014). Gambling advertising: A critical research review. The Responsible Gambling Trust.

Blais, M. \& Martineau, S. (2006). L'analyse inductive générale : description d'une démarche visant à donner un sens à des données brutes. Recherches qualitatives, 26(2), 1-18. http://www.recherchequalitative.qc.ca/documents/files/revue/edition_reguliere/num ero26(2)/blais_et_martineau_final2.pdf

Blaszczynski, A., Ladouceur, R., \& Shaffer, H. J. (2004). A science-based framework for responsible gambling: The Reno Model. Journal of Gambling Studies, 20(3), 301-317. https://doi.org/10.1023/B:JOGS.0000040281.49444.e2
Blaszczynski, A., Ladouceur, R., \& Nower, L. (2008). Informed choice and gambling: Principles for consumer protection. The Journal of Gambling Business and Economics, 2(1), 103-118. https://doi.org/10.5750/jgbe.v2i1.527

Calado, F., Alexandre, J., \& Griffiths, M. D. (2017). Prevalence of adolescent problem gambling: A systematic review of recent research. Journal of Gambling Studies, 33, 397-424. https://doi.org/10.1007/s10899-016-9627-5

Carbonneau, R., Vitaro, F., Brendgen, M., \& Tremblay, R. (2015). Trajectories of gambling problems from mid-adolescence to age 30 in a general population cohort. Psychology of Addictive Behaviors, 29(4), 1012-1021.

https://doi.org/10.1037/adb0000102

Casey, E. (2020). Gambling, status anxiety and inter-generational social mobility: Findings from the Mass Observation Archive. Sociology, 54(2), 380-396. https://doi.org/10.1177/0038038519874981

Cassidy, R. (2020). Vicious games: Capitalism and gambling. Pluto Press.

Cassidy, R. (2014). Fair game? Producing and publishing gambling research. International Gambling Studies, 14(3), 345-353. https://doi.org/10.1080/14459795.2014.971420

Castel, R. (2004). La face cachée de l'individu hypermoderne: l'individu par défaut. In N. Aubert (Eds.), L'individu hypermoderne (pp. 119-143). ERES.

Clémence, A. (2003). L'analyse des principes organisateurs des représentations sociales. In S. Moscovici \& F. Buschini (Eds.), Les méthodes des sciences humaines (pp. 393-410). PUF.

Code Criminel, LRC 1985, c C-46 (1985). https://canlii.ca/t/6d6rm

Dormeau, L. (2019). Histoire d'émotions néolibérales: Pédagogie d'une émancipation individuelle, dialectique d'une aliénation collective. Cahiers d'histoire, 36(2), 129-149. https://doi.org/10.7202/1066848ar

Dowd, D. A., Keough, M. T., Jakobson, L. S., Bolton, J. M., \& Edgerton, J. D. (2020). A longitudinal examination of gambling subtypes in young adulthood. International Gambling Studies, 20(2), 185199. https://doi.org/10.1080/14459795.2019.1697343

Edgerton, J. D., Melnyk, T. S., \& Robert, L. W. (2015). Problem Gambling and the youth-to-adulthood transition: Assessing problem gambling severity trajectories in a sample of young adults. Journal of Gambling Studies, 31(4), 1463-1485. https://doi.org/10.1007/s10899-014-9501-2

Fiedler, I., Kairouz, S., Costes, J-M., \& Weißmüller, K. S. (2019). Gambling spending and its concentration on problem gamblers. Journal of Business Research, 89, 82-91. https://doi.org/10.1016/j.jbusres.2019.01.040

Fiedler, I., Kairouz, S., \& Reynolds, J. (2021). Corporate social responsibility vs. financial interests: The case of responsible gambling programs. Journal of Public Health, 29(4), 993-1000. https://doi.org/10.1007/s10389-020-01219-w

Fine, B., \& Saad-Filho, A. (2017). Thirteen things you need to know about neoliberalism. Critical Sociology, 43(4-5), 685-706. https://doi.org/10.1177/0896920516655387

Fournier, P. (2015). La responsabilité comme mode de gouvernement néolibéral: l'exemple des programmes d'aide aux familles aux États-Unis de 1980 à nos jours. Les ateliers de l'éthique/The Ethics Forum, 10(1), 129- 154. https://doi.org/10.7202/1032732ar

Francis, L. \& Livingstone, C. (2021). Discourses of responsible gambling and gambling harm: Observations from Victoria, Australia. Addiction Research and Theory, 29(3), 212-222. https://doi.org/10.1080/16066359.2020.1867111

Gainsbury, S. (2012). Internet gambling: Current research findings and implications. Springer.

Griffiths, M. D., \& Parke, J. (2010). Adolescent gambling on the internet: A review. International Journal of Adolescent Medicine and Health, 22(1), 59-75. 
Hache, E. (2007). La responsabilité, une technique de gouvernementalité néolibérale? Raisons politiques, 4(28), 49-65. https://doi.org/10.3917/rai.028.0049

Hancock, L., \& Smith, G. (2017). Critiquing the Reno Model I-IV international influence on regulation and governments (20042015) - The distorted reality of "Responsible Gambling". International Journal of Mental Health and Addiction, 15(6), 11511176. https://doi.org/10.1007/s11469-017-9746-y

Hollén, L., Dörner, R., Griffiths, M. D., \& Emond, A. (2020). Gambling in young adults aged 17-24 years: A population-based study. Journal of Gambling Studies, 36 (3), 747-766. https://doi.org/10.1007/s10899-020-09948-z

Jodelet, D. (1989). Les représentations sociales. Collection Sociologie d'aujourd'hui. PUF.

Jodelet, D. (1994). Les représentations sociales. PUF.

Kairouz, S., \& Nadeau, L. (2014). Enquête ENHJEU-Quebec: Portrait du jeu au Québec: Prévalence, incidence et trajectoires sur quatre ans. Rapport de recherche. Fonds Québécois de Recherche - Société et Culture.

Ladouceur, R., Blaszczynski, A., Shaffer, H. J., \& Fong, D. (2016). Extending the Reno Model: Responsible gambling evaluation guidelines for gambling operators, public policymakers, and regulators. Gaming Law Review and Economics, 20(7), 580-586. https://doi.org/10.1089/glre.2016.2074

Ladouceur, R., Shaffer, P., Blaszczynski, A., \& Shaffer, H. J. (2017). Responsible gambling: A synthesis of the empirical evidence. Addiction Research \& Theory, 25(3), 225-235. https://doi.org/10.1080/16066359.2016.1245294

Livingstone, C., Rintoul, A., \& Francis, L. (2014). What is the evidence for harm minimisation measures in gambling venues? Evidence Base, (2), 1-24. https://doi.org/10.4225/50/558112A877C5D

Loto-Québec. (2021). Rapport annuel 2020-2021. https://societe.lotoquebec.com/dam/jcr:8fbd0cff-8a75-4bc0975c-69e9a2ab1bf9/rapport-annuel-2020-2021-lotoquebec.pdf

McMullan, J. L. \& Miller, D. (2009). Wins, winning and winners: The commercial advertising of lottery gambling. Journal of Gambling Studies, 25(3). 273-295. https://doi.org/10.1007/s10899-009-9120-5

Miller, H. E., Thomas, S. L., Smith K. M., \& Robinson, P. (2016). Surveillance, responsibility and control: An analysis of government and industry discourses about "problem" and "responsible" gambling. Addiction Research and Theory, 24(2), 163-176. http://dx.doi.org/10.3109/16066359.2015.1094060

Molinaro, S., Canale, N., Vieno, A., Lenzi, M., Siciliano, V., Gori, M., \& Santinello, M. (2014). Country and individual-level determinants of probable problematic gambling in adolescence: A multi-level crossnational comparison. Addiction, 109(12), 2089-2097. https://doi.org/10.1111/add.12719

Moliner, P., \& Guimelli, C. (2015). Les représentations sociales. Presses Universitaires Grenoble.

Moscovici, S. (1961). La psychanalyse, son image, son public. Presses Universitaires de France.

Paillé. P., \& Mucchielli, A. (2016). L'analyse qualitative en sciences humaines et sociales (4e ed). Armand Colin.

Reith, G. (2004). Consumption and its discontents: addiction, identity and problems of freedom. The British Journal of Sociology, 55(2), 283-300. https://doi.org/10.1111/j.1468-4446.2004.00019.x

Reith, G. (2007). Gambling and the contradictions of consumption: A genealogy of the "pathological" subject. American Behavioral Scientist, 51(1), 33-55. https://doi.org/10.1177/0002764207304856

Reith, G. (2008). Reflections on responsibility. Editorial. Journal of Gambling Issues, 22, 149-155. https://doi.org/10.4309/jgi.2008.22.12

Reynolds, J. Kairouz, S. Ilacqua, S., \& French, M. (2020). Responsible gambling: A scoping review. Critical Gambling Studies, 1(1), $23-$ 39. https://doi.org/10.29173/cgs42
Rose, N. (1999). Governing the soul. The shaping of the private self. 2nd Edition. Free Association Books.

Scholes-Balog, K. E., Hemphill, S. A., Toumbourou, J. W., \& Dowling, N. A. (2016). Problem gambling patterns among Australian young adults: Associations with prospective risk and protective factors and adult adjustment outcomes. Addictive Behaviors, 55, 38-45. https://doi.org/10.1016/j.addbeh.2015.12.016

Smith, G. (2013). The nature and scope of gambling in Canada. Addiction, 109(5), 706-710. https://doi.org/10.1111/add.12210

Statista. (2022). Market size of the gambling sector in Canada from 2011 to 2019, with forecast for 2020 and 2021 (in billion U.S. dollars). https://www.statista.com/statistics/1186307/gamblingindustry-market-size-canada/

Statista. (2020). Global gambling market gross gaming yield 20012019 (in billion U.S. dollars).

https://www.statista.com/statistics/253416/global-gamblingmarket-gross-win/

Statista. (2020). United Kingdom (UK) HMRC betting and gaming tax receipts from fiscal year 2000/01 to fiscal year 2018/19 (in billion GBP). https://www.statista.com/statistics/284338/betting-andgaming-united-kingdom-hmrc-tax-receipts/

Yani-de-Soriano, M., Javed, U., \& Yousafazai, S. (2012). Can an Industry Be Socially Responsible If Its Products Harm Consumers? The Case of Online Gambling. Journal of Business Ethics, 110(4), 481-497. https://doi.org//10.1007/s10551-012$\underline{1495-z}$

\section{Funding and Conflict of Interest Statement}

The authors declare having no conflict of interest. This study has been funded by the Fonds Québecois de Recherche - Société Culture (FRQ-SC) in collaboration with La Fondation Mise-sur-toi. Annie-Claude Savard has also received funding from Fonds de recherche du Québec - Société et culture (FRQSC), Canadian Institutes of Health Research, Social Sciences and Humanities Research Council of Canada, and Institut Universitaire sur les Dépendances within the past three years. Sylvia Kairouz is holder of the Research Chair on Gambling Studies (Misesur-toi and Concordia University). SK has received funding from Fonds de recherche du Québec - Société et culture (FRQSC), Mise-sur-toi, Canadian Institutes of Health Research, Social Sciences and Humanities Research Council of Canada, Concordia University, Canadian Funds for Innovation, and Institut Universitaire sur les Dépendances within the past three years.

\section{Author Details}

Annie-Claude Savard is associate professor in the School of Social Work and Criminology at Laval University. Her work delves into a critical study on gambling, focuses on the social construction of individual and collective responsibility, analyzes discourses in advertising and prevention messages and examines the medicalization of issues related to gambling.

Mélina Bouffard is a Doctoral Candidate in Sociology at Laval University and professor of sociology at Centre d'études collégiales de Montmagny. She has worked with Dr. Savard as the coordinator of research projects in the gambling field since 2018.

Jean-Philippe Laforge is a Master's student in Sociology at Concordia University. His research interests focus on 
medicalization, online gaming and the social construction of cyber-addiction. He has been a research assistant in the gambling field since 2019.

Sylvia Kairouz is a full professor in the Department of Sociology and Anthropology at Concordia University. She published extensively in sociology, social epidemiology and public health journals She is currently engaged in

funded research examining social inequality in gambling, social responsibility and governance. She holds an

FQRSC research chair on the study of gambling and is the head of the Lifestyle and Addiction Research Lab at Concordia University. 